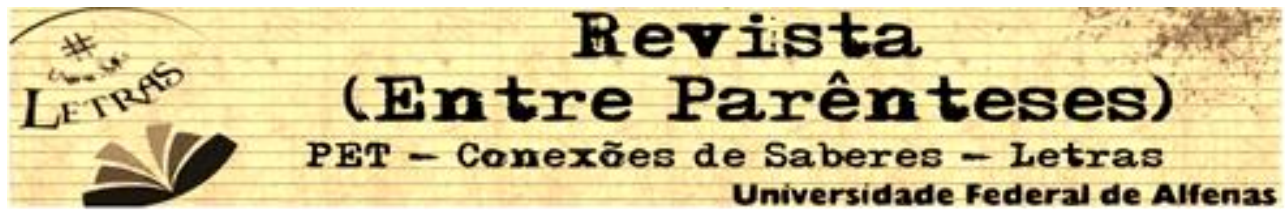

\title{
A TRADUÇÃO E A LEGENDAGEM NO DOCUMENTÁRIO “EL DERECHO DE VIVIR EN PAZ” (1999) DE CARMEN LUZ PAROT E A RELEVÂNCIA INTERCULTURAL DE VÍCTOR JARA
}

\author{
Letícia Cestari Matui ${ }^{1}$ \\ Graduanda Universidade Federal de Alfenas (UNIFAL-MG) \\ (leticiamatui@gmail.com) \\ Italo Oscar Riccardi León² \\ Universidade Federal de Alfenas (UNIFAL-MG) \\ (italoleon@uol.com.br)
}

\begin{abstract}
Resumo: O seguinte artigo tem por finalidade focalizar a tradução e a legendagem do documentário El Derecho de Vivir en Paz (Chile, 1999), dirigido por Carmen Luz Parot, que retrata a vida e morte do ícone artístico chileno Víctor Jara (1932-1973), considerando suas relevantes contribuições nos âmbitos de teatro, música, militância popular e, por fim, seu assassinato por meio de tortura durante a violenta ditadura militar liderada pelo general Augusto Pinochet. Este trabalho faz parte de um recorte do projeto de pesquisa de Iniciação Científica Voluntária (PIVIC, 2017) que visa olhar para a difusão da cultura hispano-americana em um contexto luso-brasileiro, e utiliza do mecanismo de legendagem para a língua portuguesa como uma ferramenta de mediação cultural a fim de possibilitar o diálogo entre 0 espectador e a obra cinematográfica em questão.
\end{abstract}

Palavras-chave: cultura hispânica, documentário, legendagem, tradução, Víctor Jara

\begin{abstract}
This article focus on the translation and the subtitling of the documentary 'El Derecho de Vivir en Paz' (Chile, 1999), directed by Carmen Luz Parot. It portrays the life and death of the Chilean artistic icon Víctor Jara (1932-1973), considering his relevant contribution to the theater, music and popular activism, lastly it describes his murder by torture during the violent military dictatorship led by Augusto Pinochet. This article is part of the research project of the Volunteer Scientific Initiation (PIVIC, 2017). The author's PIVIC research project aims to spread the Hispano-American culture in the Luso-Brazilian context by using the mechanism of subtitling to the Portuguese language as a tool of cultural mediation, in order to provide the dialogue between the audience and the cinematographic work in question.
\end{abstract}

Keywords: Hispanic culture, documentary, subtitling, translation, Víctor Jara

Resumen: El siguiente artículo tiene por finalidad centrarse en la traducción y en la subtitulación del documental El Derecho de Vivir en Paz (Chile, 1999), dirigido por Carmen Luz Parot, que retrata la vida y muerte del artista chileno Víctor Jara (1932-1973), considerando sus relevantes contribuciones en los ámbitos del teatro, música, militancia popular y, por último, su asesinato por medio de tortura durante la violenta dictadura militar liderada por el general Augusto Pinochet. Este trabajo hace parte del proyecto de pesquisa de Iniciación Científica Voluntaria (PIVIC, 2017), no estando todavía concluido,

\footnotetext{
${ }^{1}$ Discente de Licenciatura em Letras com habilitação na área de Espanhol pela Universidade Federal de Alfenas - UNIFAL-MG

${ }^{2}$ Doutor em Estudos Literários pelo Programa de Pós-Graduação em Letras da Universidade Federal de Minas Gerais. Professor na Universidade Federal de Alfenas - UNIFAL-MG
} 


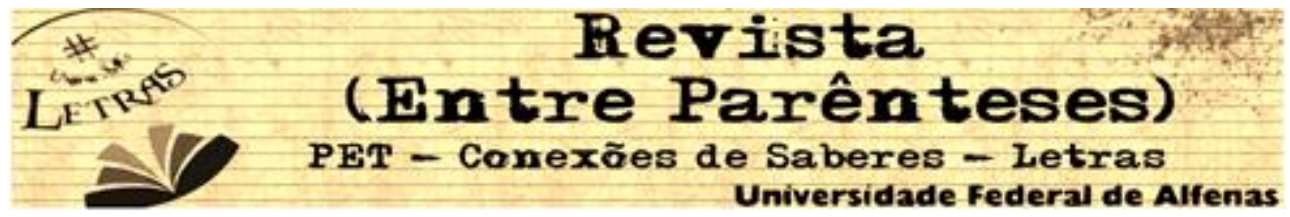

pero que, sin embargo, su enfoque está delineado hacia la difusión de la cultura hispano-americana en un contexto luso-brasileño, valiéndose del mecanismo de los subtítulos para la lengua portuguesa como una herramienta de traducción y de mediación cultural para posibilitar el diálogo de los espectadores con la obra cinematográfica en cuestión.

Palabras clave: cultura hispánica, documental, subtitulación, traducción, Víctor Jara

\section{INTRODUÇÃO}

Quase três décadas após o falecimento de Víctor Jara, foi produzido no Chile o documentário El Derecho de Vivir en Paz (1999) - obra essa que frisa a carreira e militância popular dessa expressiva personalidade artística chilena, cujo material, pelo que foi constatado e pesquisado até o presente momento, não possui uma legendagem para a língua portuguesa, aspecto singular que despertou nosso interesse por desenvolver o projeto em questão e, assim, proporcionar sua tradução para o português.

No final de 2016, fora exibido o documentário citado em uma sessão do Cineclube Unifal-MG, um projeto cinematográfico de extensão, dentro do campus sede da Universidade Federal de Alfenas. Percebendo a relevância da mensagem transmitida pela vida e obra acerca da figura de Víctor Jara e, em contraste, durante a exibição sem legendagem, observando certa evasão por parte de espectadores que não dominavam a língua estrangeira do documentário - no caso, o espanhol -, entendeu-se como crucial a necessidade de construção de um meio que proporcionasse algumas condições comunicativas para o entendimento de todo e qualquer público nativo e/ou letrado e com domínio da língua portuguesa.

Dentro de todas as peculiaridades que possam abranger o trabalho de traduzir um material de uma língua estrangeira para uma língua materna - no caso, do espanhol como língua estrangeira e a língua portuguesa como materna -, se faz necessário levar em consideração não apenas os aparatos técnicos que envolvem o desenvolvimento de tal iniciativa, mas principalmente o que acarreta traduzir e legendar uma produção cinematográfica que podemos considerar de imensa bagagem e referencial cultural para a história do Chile e, também, da América Latina. 


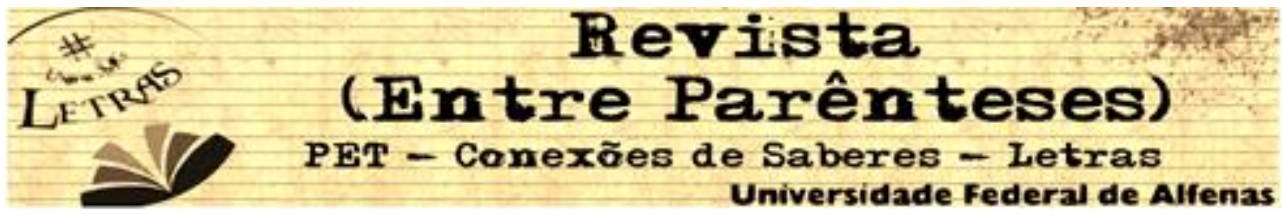

Desta maneira, o artigo visa, de forma sucinta, juntamente com destacar a figura de Víctor Jara, dar a conhecer e enfatizar aspectos considerados pertinentes a todo o universo que abrange a tradução e legendagem, assim como explanar os motivos que impulsionaram a realização do trabalho e de nossa preocupação em difundir a história de um talentoso ícone expressivo da cultura popular chilena e latinoamericana que teve, infelizmente, sua trajetória interrompida pela chegada ao poder da brutal e desumana ditadura militar pinochetista.

\section{APROXIMAÇÃO A VÍCTOR JARA E SEU CONTEXTO HISTÓRICO- CULTURAL ${ }^{3}$}

Nascido em 28 de setembro de 1932, Víctor Jara era o mais novo de seis irmãos, filho de um pai trabalhador de campo e sua mãe, cantora. Iniciou sua carreira artística por meio do seu ingresso na Universidad de Chile, e lá principiou o desenvolvimento de seus dois maiores interesses: o teatro e a música, que sempre caminharam simultaneamente em sua vida.

Em 1954, viajou com um grupo de amigos para o norte do país a fim de investigar a música popular em suas raízes. Em 1958, associou-se ao grupo musical folclorista denominado Cuncumén, progredindo cada vez mais em seu conhecimento acerca do universo folclorista, redescobrindo o patrimônio cultural através da música herdada de sua mãe. Ainda no âmbito musical, teve grande influência de nomes relevantes do folclore nacional tal qual Violeta Parra, compositora de canções como "Qué dirá el Santo Padre" e "Al centro de la injusticia" - canções autenticamente populares, sendo elas musical, poética e culturalmente valiosas. Também participou do grupo musical Quilapayún, igualmente voltado para a raiz folclórica do país. No que contempla suas contribuições teatrais, em 1956 ingressou na Escola de Teatro da

\footnotetext{
${ }^{3}$ As informações acerca da figura de Víctor Jara em seus pormenores foram retiradas principalmente da página virtual da Fundación Víctor Jara (2017) <http://fundacionvictorjara.org/sitio/>, uma fonte de consulta que consideramos importantíssima e de expressivo mérito como embasamento de informações confiáveis no que se diz respeito ao artista chileno.
} 


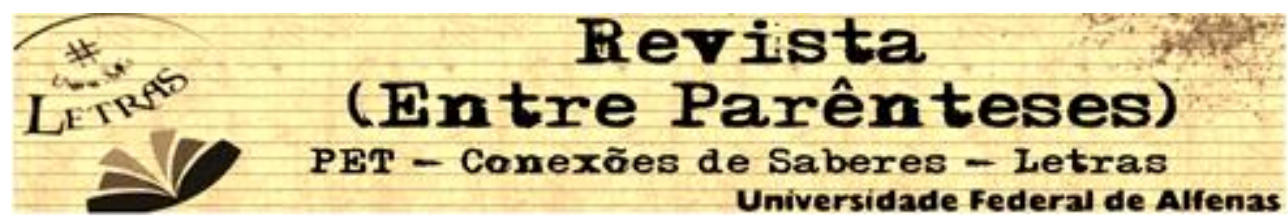

Universidad de Chile e, posteriormente, entre 1962-1963, estudou direção teatral no Instituto de Teatro da Universidad de Chile, montando peças como Animas de Día Claro de Alejandro Sieveking - peça essa que se converteu em um clássico e perdurou em cartaz por seis anos.

Desde essa época, já apresentava seu nacionalismo enraizado e sua preocupação perante o povo chileno, apontando a singularidade das pessoas do campo e expondo as injustiças que acercavam a população por meio da exploração e desigualdade social. Em uma entrevista a Carmen Grandé [s.d.], uma periodista chilena, Víctor Jara sintetiza algumas de suas ideias dizendo:

Não é justo que as crianças morram de fome. Não é justo que um homem dê sua vida trabalhando a terra que não o pertence e que quando morre não tenha um pedaço onde descansem seus ossos (...). A injustiça e o engano devem terminar. A longa e humilhante escravidão da América Latina caminha irreversivelmente para a libertação ${ }^{4}$.

Ainda no que se diz respeito a suas reflexões político-sociais, Víctor Jara compôs o movimento social encabeçado por Pablo Neruda denominado La Nueva Canción Chilena, que surgiu em meados de 1960 e consolidou-se definitivamente no início da década de 70, com objetivos de libertação por parte do povo chileno de influências imperialistas exacerbadas e incentivo a valorização da produção de cultura nacional; além disso, também era diretamente vinculado à Unidade Popular movimento político que apoiou a candidatura de Salvador Allende durante o processo de escolha presidencial; se apresentou, juntamente com o grupo Quilapayún, em 1968 em manifestações a favor de uma reforma universitária que fora duramente reprimida. Ademais, com o lançamento seu primeiro L.P. intitulado "Pongo en tus manos

\footnotetext{
${ }^{4}$ In: MEMORIA CHILENA, centro de acervo digital que oferece documentos e conteúdos originais a fim de agrupar a história coletiva chilena que formam a identidade do país. Jornal não informado, tradução nossa. ["No es justo que los niños mueran de hambre. No es justo que un hombre dé su vida trabajando la tierra que no lo pertenece y que cuando muere no tenga un pedazo donde descansen sus huesos (...). La injusticia y el engaño deben terminar. La larga y humillante esclavitud de Latinoamérica camina irreversiblemente hacia la liberación"].
} 


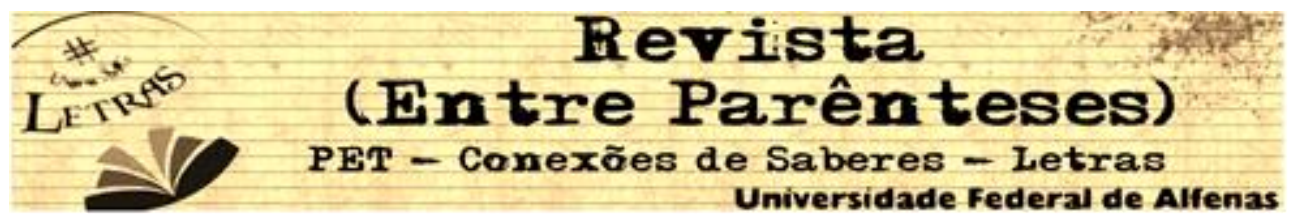

abiertas", em 1969, apenas se acentuou suas ideologias populares, tornando-as evidentes publicamente e, com os tempos de repressão e violência que estariam por vir no território chileno, Víctor Jara se tornara um dos símbolos artísticos de resistência popular.

Em 1973, os militares, liderados pelo general Augusto Pinochet, implantaram um golpe militar, retirando o então presidente Salvador Allende do poder. Os motivos que levaram ao golpe se suscitam em um geral descontentamento por parte das elites chilenas e outros setores que não enxergavam no então presidente uma representação positiva em prol de seus interesses políticos, já que Allende, em seu governo, tomou uma série de providências que faziam jus ao seu plano políticosocial - que tinha como base a instauração de aspectos que, muitas vezes, eram considerados de viés socialista, caracterizando a chamada via chilena - mas que não se mostravam necessariamente satisfatórios para outros grupos, considerando que a então chamada revolução chilena de Allende:

(...) nacionalizou as 'riquezas básicas' do Chile: as minas, que eram responsáveis por três quartos dos lucros das exportações do país (...) e quase todos os bancos privados chilenos, os tesouros do pequeno número de 'clãs' financeiros que controlavam a economia capitalista do país. Com a ajuda de uma revolução que partiu dos trabalhadores, dos camponeses e dos moradores das favelas, cujas ações diretas haviam transformado a toma - ou ocupação - na marca registrada da revolução chilena, o 'governo do povo' de Allende conseguiu o controle de muitas das maiores produtoras e distribuidoras do país e realizou a mais rápida e extensa reforma agrária da história sem uma revolução violenta. (WINN, 2010, p.18)

Levando em conta tais medidas, como ressalta Peter Winn (2010), uma série de manifestações contrárias as ações de Salvador Allende começaram a surgir, principalmente por via de protestos das elites chilenas - mas esse descontentamento só ganhou forças significativas quando os Estados Unidos da América também categorizaram as ações do então presidente como desfavoráveis para um diálogo econômico entre os dois países. Isso fez com que as elites procurassem uma solução 


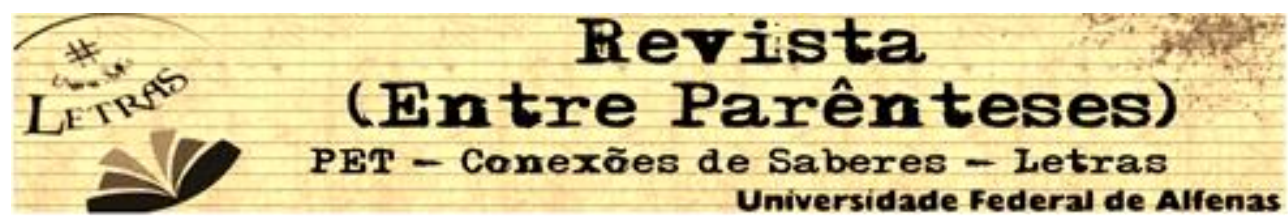

nos quartéis e apoiassem, de modo geral, um golpe militar. Tendo isso em vista, as Forças Armadas foram atraídas para esse conflito político que se estabelecera no território nacional e, assim, instauraram com êxito a ditadura militar, interrompendo a revolução considerada pacífica de Salvador Allende por meios violentos.

Esse novo cenário instituído no Chile acarretou uma série de ações radicalmente contrárias àquelas do antigo presidente da nação, e os anos que sucederam o golpe foram marcados pela repressão e violência àqueles que se posicionavam contrários ao governo militar - as Comissões de Verdade Oficiais estimaram um número de 3.178 mortos ou desaparecidos durante o período ditatorial, assim como pelo menos 28 mil torturados. Ademais, estipulou-se a média de cem mil pessoas presas e interrogadas e, dentre esse número, provavelmente se infringiu algum tipo de violência para com as mesmas, como acrescenta Winn em sua obra. E é justamente dentre esses números de vítimas da ditadura militar chilena que se encontra Víctor Jara - por conta de sua ideologia e pensamento político-social que se fizeram públicas durante sua carreira artística, Víctor Jara se tornara incluso na esfera daqueles que representavam uma firme contraposição ao governo militar.

Joan Jara ${ }^{5}$ (Chile, 2007), esposa de Víctor Jara, relata os acontecimentos perante seus olhos, assim como a última vez que vira seu marido vivo: na manhã na qual se instaurou o golpe, Víctor Jara se direcionou para seu local de trabalho, a Universidad Técnica, seguindo instruções da CUT. Seu desaparecimento, na mesma data, não ficara esclarecido, até que em 12 de setembro de 1973, Joan Jara, por meio de um telefonema, tomou conhecimento do paradeiro de seu marido, que tinha sido preso e transportado para o Estadio Chile. Desde então, as condições de encarceramento, assim como o tratamento que Víctor Jara recebera durante o período que ficou sob a vigilância militar são imprecisas. No dia 18 de setembro de 1973,

\footnotetext{
${ }^{5}$ Joan Jara, nascida como Joan Alison Turner (1927-) na Inglaterra, teve em sua trajetória o ballet e seu ativismo político. Fora nacionalizada no Chile e casou-se com Víctor Jara em meados de 1960, com quem permaneceu até o assassinato do artista em 1973. É fundadora da Fundación Víctor Jara, que faz jus a imagem de seu falecido marido.
} 


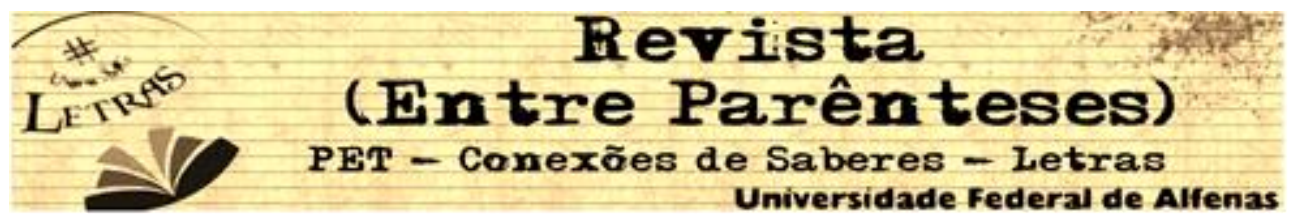

chega ao seu conhecimento que seu marido fora assassinado - um jovem, membro das Juventudes Comunistas, dirigiu-se até sua casa para lhe enviar a mensagem de que haviam encontrado o corpo de Víctor Jara no necrotério - Joan Jara conseguiu reclamar o corpo de seu marido e enterrá-lo. A mídia, ao fazer menção da morte do artista, posicionou-se de forma que levava ao entendimento do público que Víctor morrera de maneira plácida, como aponta Joan Jara em um trecho de sua obra:

No dia seguinte o jornal La Segunda publicou um breve parágrafo em que informava sobre a morte de Víctor como se tivesse falecido pacificamente na cama: "O funeral foi de caráter privado e compareceram somente familiares". Depois todos os meios de comunicação receberam a ordem de não voltarem a mencionar Víctor. ${ }^{6}$

Em 1999, após 26 anos do assassinato de Víctor Jara, Carmen Luz Parot produziu o documentário El Derecho de Vivir en Paz, ressaltando a trajetória do artista chileno desde sua infância, sua importância no âmbito teatral e musical, sua militância política, até sua morte por meio de tortura, destacando uma das figuras mais importantes não apenas para o âmbito nacional chileno, como também para a história de uma América Latina marcada por regimes ditatoriais em seus diversos países que a compõe - e dentre esses países, encontra-se o Brasil, que semelhantemente possui um golpe e ditadura militar traçando uma marca em sua história nacional, perdurando por 21 anos.

\section{A LEGENDAGEM COMO MECANISMO DE MEDIAÇÃO CULTURAL}

É justamente dentro desse contexto que a obra cinematográfica encontra sua necessidade de uma legendagem para a língua portuguesa, viabilizando a leitura e compreensão plena das informações transmitidas pelo documentário por parte de

\footnotetext{
${ }^{6}$ JARA, 2007, p. 250, tradução nossa. ["Al día siguiente el diario La Segunda publicó un breve párrafo en el que informaba de la muerte de Víctor como si hubiera fallecido plácidamente en la cama: 'EI funeral fue de carácter privado y sólo asistieron los familiares'. Después todos los medios de difusión recibieron la orden de no volver a mencionar a Víctor."]
} 


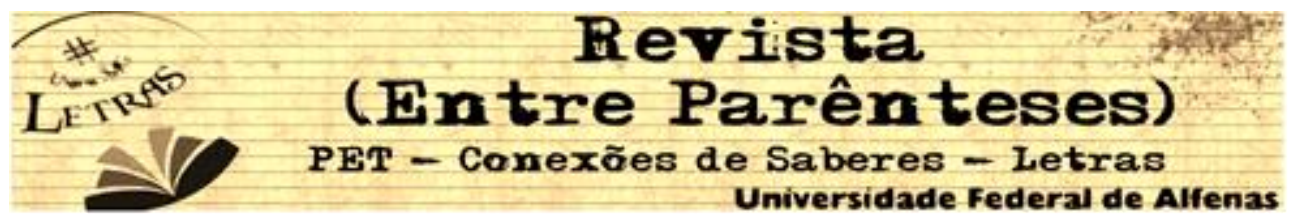

um público que não possui domínio sobre a língua espanhola. Nessa esfera, é de relevância salientar a necessidade de que o povo brasileiro abrace sua identidade latina, o que muitas vezes se perde em meio a uma barreira imaginária existente entre o Brasil e os demais países da América do Sul.

De forma a exemplificar, tal barreira pode ser entendida pela divisão linguística existente por um território falante da língua portuguesa, majoritariamente, enquanto seus países vizinhos se consolidam, de forma geral, pela língua espanhola; além disso, a construção política do Brasil se concebeu distante dos países em dados momentos, assegurando um relativo estranhamento perante o outro e se distanciando de sua identidade latina. Mas, se existem divergências significativas entre o Brasil e os demais países da América do Sul, em especial aqueles que também compõem o Cone Sul, é igualmente possível apontar semelhanças: se abrangendo uma perspectiva histórica, grosso modo, acerca da consolidação dos países latinoamericanos, é concebível lembrar que países da Europa vieram para o continente e impuseram sua cultura, assim como a sua língua; que foram implantadas ditaduras militares em todos os países do Cone Sul; ou, ainda, lembrar de fatores econômicos como, por exemplo, a consolidação do MERCOSUL, viabilizando um diálogo mais amplo entre os países que o compõe e que, de modo geral, incentivou a ampliação do ensino de espanhol nas escolas brasileiras.

O isolamento existente entre o brasileiro e os demais povos latinoamericanos também se baseia na falta de conhecimento amplo existente acerca da cultura hispano-americana - cenário esse que vem se revertendo ao longo dos últimos anos, mas que, ainda assim, demanda um incentivo cada vez mais acentuado. Nesse sentido, é importante enfatizar que

Com a globalização, a importância da cultura hispânica se destaca, uma vez que as pessoas estão em busca de novas informações. Além de receber influencias da Espanha, sabe-se que geograficamente 0 Brasil possui diversas fronteiras com países cuja língua oficial é o Espanhol. E está explicito que essa proximidade faz com que os brasileiros tenham afinidade com essa cultura, seja através das 


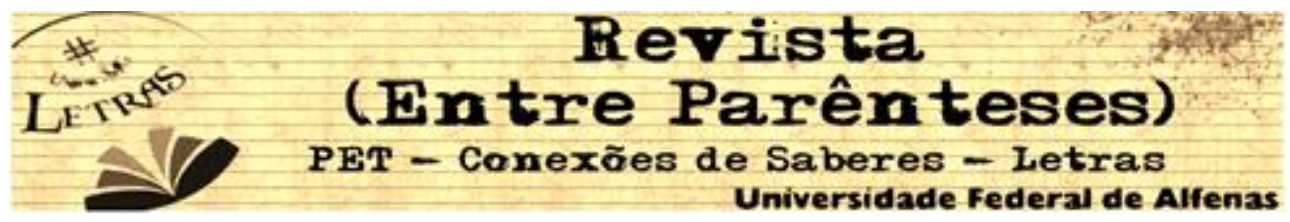

músicas, literatura, culinária, manifestações artísticas, culturais e etc. (ARAUJO, 2010, p. 246).

De forma a complementar, em um mundo em que as relações já não se fazem mais de forma estritamente local, ou seja, em que as relações multiculturais se expandem gradativamente, é interessante ressaltar que, em dados fornecidos por Baeninger (2012, p. 9-18), o Chile se encontra como o segundo país de escolha dos brasileiros como destino migratório. Isto é, de certa forma, uma presença e diálogo de maneira direta entre os dois olhares em questão - o indivíduo que possui a língua portuguesa como língua materna está interagindo não somente com a língua espanhola, mas também com a cultura chilena, considerando a importância vital na integração entre língua e sociedade. Todavia, apenas a multiculturalidade muitas vezes não dá conta do conhecimento que se faz necessário adquirir quando se trata de uma interação com a cultura e sociedade do outro, e as relações interculturais se encaixam perfeitamente nesse âmbito, salientando esse diálogo cultural que se mostra cada vez mais essencial.

Assim, além de ter em vista a magnitude que carrega a difusão da cultura hispano-americana, que amplia os horizontes interculturais do brasileiro, da mesma forma que faz com que o mesmo reconheça a história de seu continente marcado por luta e resistência, a legendagem do documentário também trabalha como mecanismoponte para uma interação obra-interlocutor inteiriça. Por esse ângulo, parafraseando Gorovitz (2006, p. 13-29), entende-se que o espectador, quando se submete a uma experiência cinematográfica, interage com a obra de tal forma que, mesmo inconscientemente, participa da decodificação da mensagem. Ademais, ao se estabelecer essa comunicação, a troca de informações também se faz inevitável e o receptor, a partir das noções adquiridas, desencadeia e atualiza outras memórias dentro do seu imaginário, fortificando o laço existente entre o familiar e o desconhecido, enlaçando dois horizontes, criando um sentido novo. 


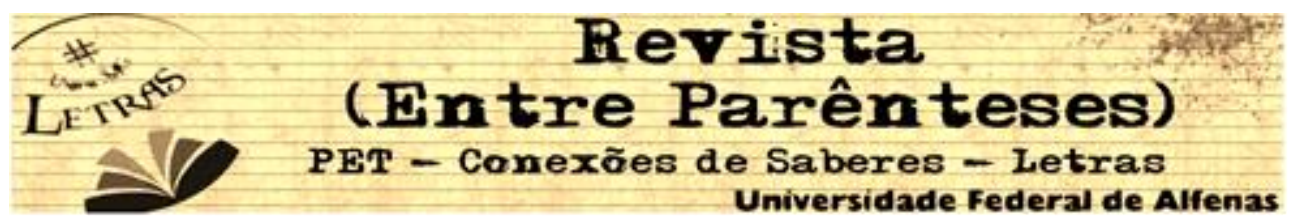

Para mais, a troca de informações deixa de ser uma experiência pessoal e passa a compor uma rede de conhecimentos entre diversos indivíduos que compartilham dos sentimentos e ideias transmitidas pela obra, definindo novas referências culturais de um imaginário coletivo. A partir dessa perspectiva, o cinema permite que o sujeito valorize a cultura do outro por meio da imagem, já que é dentro dessa nova perspectiva cultural coletiva que se permite entender e se aproximar de um suposto desconhecido, renovando o olhar do homem individual e fortalecendo o vínculo do mesmo com a sociedade global.

Mas, nesse caso, a fim de que toda a comunicação entre obra e espectador seja satisfatória, encontra-se a legendagem como um suporte à experiência cinematográfica, permitindo a absorção máxima da mensagem transpassada pela obra, já que se trata de um documentário que se concebe em uma língua estrangeira ao brasileiro. Em síntese,

A tela é o palco para a encenação de mitos e símbolos presentes e atuantes na sociedade. As realidades urbanas são apresentadas com suas características locais, porém retratam contextos compartilhados. Assim, violência, vida quotidiana, solidão, fluxos de massa, consumo, etc. pertencem ao horizonte transcultural, no qual se reconhecem os espectadores mais diversos. A mensagem legendada oferece, inserido nesse quadro, um texto que viabiliza o reconhecimento de situações (GOROVITZ, 2006, p. 47-48, grifo nosso).

Nesse sentido, é importante destacar, conforme Gorovitz (2006, p. 64) que a legendagem não é, de forma alguma, uma novidade cinematográfica, um mecanismo moderno inserido recentemente - pelo contrário, a legendagem já existia no universo cinematográfico de forma anterior à fala, a levar em consideração a época primordial do cinema, visto que, dentro desse contexto, a legendagem era utilizada como suporte em uma época em que os meios técnicos ainda se viam precários, auxiliando na transmissão da mensagem a ser propagada.

Agora, voltando o olhar para a legendagem em um contexto cinematográfico sob a ótica luso-brasileira em que uma obra fora concebida em uma 


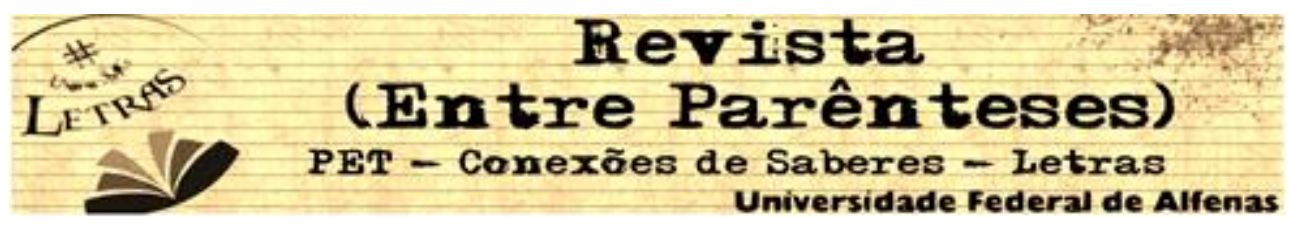

língua estrangeira, a legenda será projetada como um mediador cultural, considerando que é através dela que o espectador terá pleno reconhecimento das situações transpassadas pela obra - tais como os relatos daqueles que eram próximos a Víctor Jara, como amigos de infância, que relatam seu comportamento educado, tranquilo, estudioso; amigos que o acompanharam durante sua trajetória na Universidad de Chile, assim como o início de seu interesse pelo folclore nacional; relatos de sua esposa que, dentre tantos depoimentos importantes, narra também o momento perturbador quando fora reconhecer o corpo de seu marido no necrotério. Esses são apenas alguns exemplos das informações transpassadas pela obra cinematográfica, cheia de relatos e imagens que fazem o espectador embarcar em uma trajetória que envolve o ambiente, a vida, as pessoas e as histórias do universo de Víctor Jara. E é a partir da legendagem que se possibilitará a aproximação e o conhecimento desse universo, da cultura do outro e apreciação da mesma; é com essa ferramenta que se viabilizará o contato concreto por parte daqueles que não possuem ou não têm acesso ao domínio da língua-meta - ressaltando, aqui, o espanhol como língua estrangeira.

\section{CONSIDERAÇÕES FINAIS}

Concluindo, entende-se que a falta de um suporte traduzido para a língua materna em um contexto luso-brasileiro, o português, poderia inviabilizar ao público a compreensão total da obra em questão e, para além disso, percebe-se que, mais do que em seu viés técnico, a falta da legendagem priva o acesso de informações aos indivíduos que não possuem domínio da língua estrangeira utilizada na produção cinematográfica, acentuando, talvez, a tal barreira imaginária que pode existir entre 0 brasileiro e os demais países do Cone Sul, que pouco reconhece e explora a sua identidade latina, sendo essa tão importante para que se concretize aquilo que nos forma como unidade em um continente marcado por suas singularidades, por suas lutas e preconceitos. 


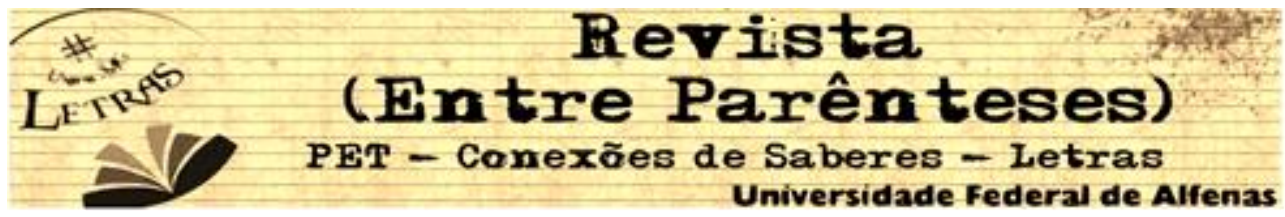

Ademais, acentua-se também a divisão existente entre diferentes grupos sociais que possuem diferentes níveis de acesso à informação e, no caso, aprendizagem de línguas estrangeiras. Dessa forma, é imprescindível salientar que, apesar da existência de discussões acerca da tradução em seu caráter geral, se é "correto" ou não traduzir - já que é de conhecimento daqueles que possuem domínio de alguma língua estrangeira e que talvez, já se depararam com traduções muitas vezes de cunho duvidoso, que algumas perdas de caráter linguístico podem ocorrer em meio a expressões típicas, por exemplo. Mas, se voltado o olhar para as questões sociopolíticas que envolvem a tradução de um material - aqui, no caso, a tradução e legendagem do documentário El Derecho de Vivir en Paz (Chile, 1999) -, entende-se que a tradução vai muito além do simples manejar de um texto em suas peculiaridades linguísticas, transformando-se na ferramenta necessária para a difusão daquilo que se considera informação e, mais do que isso, conhecimento, aprendizado, constituição e formação da cidadania. Aqui, a tradução entra como forma de abrir caminhos para aqueles que não dominam uma língua estrangeira, mas que nem por isso deveriam ser privados do conhecimento, do enriquecimento de sua bagagem cultural e de seus referenciais do imaginário coletivo.

Nenhuma tradução deveria ser considerada "fácil", e a tradução do documentário El Derecho de Vivir en Paz (1999) não poderia ser diferente. As dificuldades estão marcadas pelo constante esforço de manter a legendagem o mais fiel possível com a mensagem transpassada pela obra, para que não haja lacunas significativas que interfiram naquilo que justamente o trabalho se propõe a fazer: viabilizar o entendimento pleno do documentário em questão. Nesse sentido, é interessante ressaltar o aprendizado linguístico que esse processo de tradução acarreta, já que adentrar as peculiaridades linguísticas de um país se transforma em conhecimento constante para aqueles que se dispõe a voltar a atenção às mesmas. Porém, apesar das dificuldades que possam surgir, visando a propagação da história de um ícone cultural que se configura como referência tanto com seus projetos artísticos, como também com sua trajetória de militância e resistência popular, e 


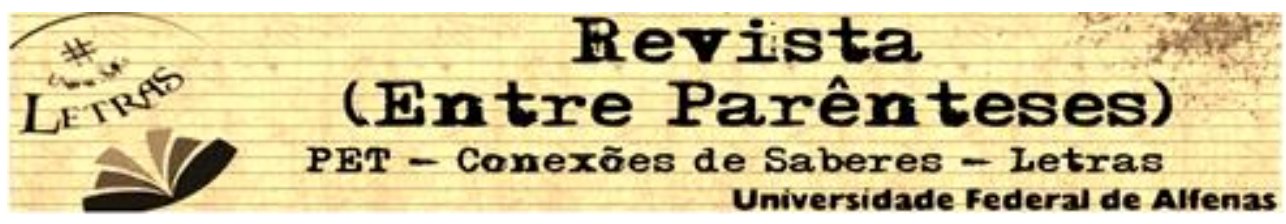

considerando de grande importância que se faça acessível o adquirir desse conhecimento, entende-se como imprescindível que se concretize, desenvolva e pratique essa tradução, assim como a legendagem, afinal, entende-se que essa permite que o falante da língua portuguesa compreenda todo o universo que abrange uma figura-ícone para a cultura latino-americana.

Nesse processo de tradução, que envolve um cuidado imenso daqueles que se dispõe a manter a mensagem o mais fiel possível comparada à original, é impossível não se envolver com aquilo que abrange o conteúdo a obra, proporcionando um trabalho que ultrapassa o técnico e nos enriquece em cultura e amplia as perspectivas de um universo hispano-americano que possui tantos elementos enriquecedores e que ainda se encontra tão pouco explorado, principalmente sob a ótica luso-brasileira, que necessita de muito empenho para alcançar todos os âmbitos que engrandecem um continente repleto de tradição, de história e de luta.

Dentro dessa esfera, o contato com a trajetória de Víctor Jara, uma personalidade tão marcante para a militância artística popular da América Latina, não poderia deixar de emocionar aqueles que buscam resgatar essa identidade latina constantemente, se envolvendo com os pormenores de uma época tão sombria para a história do Chile e de todos os países do Cone Sul que se configuraram em contextos ditatoriais em dados momentos históricos, mas que também ressalta a riqueza de um continente que, apesar das diferenças, não abre mão daquilo que nos singulariza como América Latina.

Como já dissera Víctor Jara - o que fora muito bem documentado no site da Fundación Víctor Jara (2017), que faz jus a sua memória -, a "América Latina deve ser uma grande casa. A união deve ser forte" [“América Latina debe ser una gran casa. La unión debe ser fuerte"]. Sob uma ótica luso-brasileira, a troca de informações com um documentário dessa magnitude assegura a apreensão máxima da cultura do outro, incentivando o respeito às diferenças, apontando as semelhanças existentes e, consequentemente, ampliando os horizontes, perspectivas e fortificando essa união. 


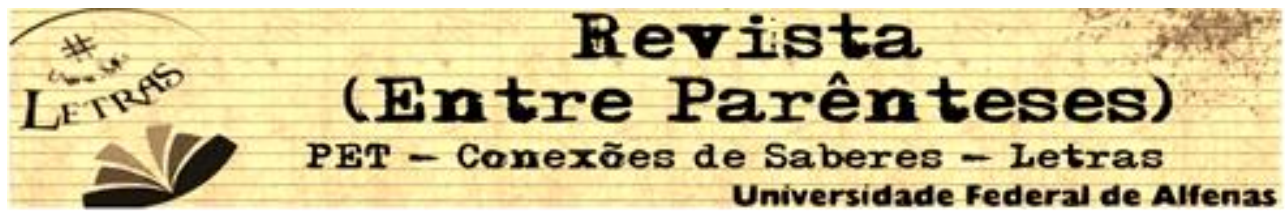

\section{REFERÊNCIAS}

ARAUJO, C. M. A. O Ensino de Espanhol no Brasil: História de um processo em construção. In: Anais do Seminário de Pesquisa em Ciências Humanas. P. 240-252. 2010.

Disponível

em:

<http://www.uel.br/eventos/sepech/arqtxt/PDF/catyamarques.pdf>. Acesso em: 22 mar. 2017.

BAENINGER, R. O Brasil na rota das migrações latino-americanas. In: BAENINGER, R. (org.). Imigração Boliviana no Brasil. Campinas: Núcleo de Estudos de População-Nepo/Unicamp; Fapesp; CNPq; Unfpa, 2012, p. 9-18.

FUNDACIÓN Victor Jara. Disponível em: <http://fundacionvictorjara.org/victorjara/>. Acesso em: 16 ago. 2017.

GOROVITZ, S. Os labirintos da tradução: a legendagem cinematográfica e a construção do imaginário. Brasília: Editora Universidade de Brasília, 2006.

GRANDÉ, C. Victor Jara: el canto, un arma de lucha, 19--. Disponível em: <www.memoriachilena.cl/602/w3-article-7680.html\#documentos>. Acesso em: 22 mar. 2017.

JARA, J. Victor. Un canto inconcluso. Santiago: Editora Libros Arces-Lom, 2007.

WINN, P. A revolução chilena. São Paulo: Ed. UNESP, 2010. 